\begin{tabular}{|l|l|}
\hline & \\
\hline
\end{tabular}

ATUALIDADE POLITITICA DA TEORIA CRÍTICA

\title{
Condições pós-coloniais abusivas e as tarefas da Teoria Crítica
}

\author{
Abusive postcolonial conditions and the tasks of Critical Theory \\ Condiciones poscoloniales abusivas y las tareas de la Teoría Critica
}

\section{Ina Kerner ${ }^{1}$}

orcid.org/0000-0001-9974-4648

kerner@uni-koblenz.de

Recebido: 19 nov. 2019

Aprovado: 17 jan. 2020.

Publicado: 22 fev. 2022

\section{(c) (1)}

Artigo está licenciado sob forma de uma licença Creative Commons Atribuição 4.0 Internacional.
Resumo: A Teoria Critica da Escola de Frankfurt praticamente omitiu de suas discussões o colonialismo europeu, e também por seu legado ela até o momento só se interessa de modo hesitante. O presente texto parte do pressuposto que esse desinteresse prejudica uma análise crítica da sociedade. Ele indica em que direções poderia desenvolver-se uma Teoria Crítica levando a sério nossas constelações pós-coloniais. No texto são abordadas a colonialidade do poder (Aníbal Quijano), interconexões entre modernidade, racismo e democracia (Achille Mbembe), as implicações do imperialismo para o moderno sistema estatal (James Tully) bem como as interconexões entre pós-colonialismo e sexualidade (Gatari Spivak).

Palavras-chave: Pós-colonialismo. Colonialidade. Racismo. Imperialismo. Sexualidade.

Abstract: The Critical Theory of the Frankfurt School has largely ignored to address European colonialism, and so far it has also been hesitant to take an interest in its legacy. The present article assumes that this lack of interest is detrimental to a critical analysis of society. It shows in which directions a Critical Theory could be developed in order to take our post-colonial constellation seriously. The coloniality of power (Anibal Quijano), connections between modernity, racism and democracy (Achille Mbembe), the implications of imperialism for the modern state system (James Tully) and connections between postcolonialism and gender (Gayatri Spivak) are discussed.

Keywords: Post-colonialism. Coloniality. Racism. Imperialism. Gender.

Resumen: La Teoría Critica de la Escuela de Frankfurt en gran medida ha dejado de abordar el colonialismo europeo, y hasta ahora también solo se ha interesado tímidamente por su legado. El presente artículo asume que esta falta de interés va en detrimento de un análisis critico de la sociedad. Muestra en qué direcciones podria desarrollarse una Teoria Critica que se tome en serio nuestra constelación poscolonial. Se discute la colonialidad del poder (Aníbal Quijano), las conexiones entre modernidad, racismo y democracia (Achille Mbembe), las implicaciones del imperialismo para el sistema estatal moderno (James Tully) y las conexiones entre poscolonialismo y género (Gayatri Spivak).

Palabras clave: Poscolonialismo. Colonialidad. Racismo. Imperialismo. Género.

\section{Introdução²}

Se seguirmos uma formulação clássica de Max Horkheimer feita nos anos 1930, então uma teoria crítica da sociedade dada é perpassada por um "interesse em condições razoáveis"; uma atitude crítica, ademais, "não 
tem apenas a intenção de remediar quaisquer condições abusivas; ao contrário, estas lhe parecem ligadas necessariamente a toda organização da estrutura social" (Horkheimer 1980). ${ }^{3}$ À época, vastas partes do mundo estavam moldadas pelo colonialismo; hoje, na maioria destas regiões lidamos com condições pós-coloniais, a despeito das diferenças que possam existir entre elas. Embora na época a Escola de Frankfurt tenha tido pouco interesse crítico pelo colonialismo, a não tematização de condições pós-coloniais abusivas parece cada vez menos compativel com o projeto de uma teoria crítica. Isso certamente se deve a que, dentre outras razões, nas últimas décadas lograram estabelecer-se distante de Frankfurt outras perspectivas de formação crítica de teoria, dentre elas aquelas em que a reflexão crítica sobre história, atualidade e consequências do colonialismo europeu bem como do imperialismo ocidental recebem um lugar de destaque. Obviamente também aqui se é motivado por um interesse em condições razoáveis e também se toma aqui como ponto de partida a convicção de que se está diante de algo mais do que tão somente condições abusivas, que ademais relações pós-coloniais de poder e dominação estejam relacionadas de modos múltiplos e complexos com todo o estabelecimento da estruturação global da sociedade - o que desafia análises críticas de padrões de pensamento e sistemas de conhecimento bem como de formações sociais, estruturas econômicas e constelações políticas. A teoria pós-colonial que está em tela aqui pode ser compreendida hoje como um projeto ramificado, de orientação transdisciplinar de uma teoria crítica global, capaz também de contribuir com uma Teoria Crítica em sentido estrito, isto é, de corte frankfurtiano. No que segue pretendo esboçar em que essa contribuição poderia consistir, e isto com relação a diferentes campos temáticos - da economia, passando por democracia e direito, até questões de política transnacional e feminis- ta - tomando como base os trabalhos de autoras e autores que, com diferentes ênfases, colocam no centro de suas análises críticas aspectos das relações pós-coloniais de poder e dominação. Com relação a todos esses campos temáticos, defendo a tese de que uma perspectiva teórica pós-colonial é especialmente adequada para uma análise critica da política, porquanto ela toma para si a tarefa desvelar as consequências da constituição colonial da moderna estruturação da sociedade, a saber, para ex-colônias ou pós-colônias, para estados coloniais de outrora bem como para nossa constelação política global. Com isso teorias pós-coloniais estão em condições de interpretar situações abusivas atuais nas referidas áreas temáticas como expressões especificas da estrutura colonial profunda da modernidade ocidental. Esta forma de tomar a sério as condições estruturais da política atual só pode contribuir para um interesse em condições razoáveis.

\section{Sobre a colonialidade do poder}

O sociólogo peruano Aníbal Quijano, que inicialmente se tornou conhecido nas regiões de língua alemã vinculado à teoria da dependência, mas que nas últimas duas décadas é discutido, sobretudo, como representante da abordagem decolonial, portanto, das abordagens pós-coloniais relacionadas com a América Latina, descreve a instituição colonial da moderna estrutura social como "colonialidade do poder".4 Com isso ele se refere a uma forma de poder e dominação que foi estabelecida (na América Latina) através do colonialismo europeu, mas que sobreviveu ao fim formal da dominação colonial. De acordo com Quijano, a colonialidade do poder abrange a totalidade da formação econômica e social. Sua base e seu instrumental - e nesse ponto o teórico decolonial Quijano se diferencia da antiga teoria da dependência - são classificações raciais "naturalistas" da população mundial a serviço da

\footnotetext{
3 N. T.: A autora trabalha com a contraposição entre Mißstand (condição abusiva) e vernünftiger Zustand (condição razoável); por esta razão optou-se por divergir ligeiramente da tradução publicada em Os pensadores porquanto "inconvenientes" seria um eufemismo para o que no que segue é descrito.

4 Nos anos 1970 foram publicados três textos de Quijano em alemão: "Imperialismo y capitalismo de estado: el caso de Perú"; "Polo marginal" y "mano de obra marginal"; e Poder y democracia en el socialismo. Aquilo que hoje é descrito como "abordagem decolonial" ainda não se encontra nesses textos. A respeito da abordagem decolonial, além de uma série de outras publicações em espanhol, ver Mignolo (2005), Moraña, Dussel e Jáuregui (2008), Mignolo e Escobar (2013). Sobre a obra de Quijano, ver Quintero e Garbe (2013) e Quijano (2014).
} 
manutenção do poder e da dominação europeias, e com isso, da manutenção do racismo institucionalizado em nível global (Quijano 2007). Segundo Quijano, com o início do colonialismo europeu na América Latina pode formar-se sobre esta base um padrão de poder e dominação com dois eixos centrais: racismo-mais-capitalismo. Por um lado, "um novo sistema de dominação social, que se constituiu sobre a ideia da raça, um construto intelectual que naturalizava a relação entre os novos dominadores com os conquistados e colonizados, isto é: que permitia compreendê-la como 'natural'". Por outro, um novo sistema social de exploração que "conectava estruturalmente entre si todas as formas de exploração entre si para, sob a hegemonia do capital, produzir mercadorias para o mercado mundial" (Quijano 2010). Esses dois eixos estavam conectados em um sistema econômico que integrava todas as formas até então existentes de controle e exploração do trabalho - escravidão, servidão, reciprocidade, assalariamento - e as colocava a serviço da produção de bens para o mercado mundial (Quijano 2016, 29s; Quijano 2014, 777ss). As diferentes formas de trabalho foram conotadas 'racialmente': enquanto o trabalho assalariado era reservado aos brancos, aqueles segmentos populacionais que eram classificados como 'indios' foram submetidos à servidão; a isso se acrescentou a produção baseada na escravidão, para cuja finalidade pessoas da África foram traficadas para as Américas e classificadas coletivamente como 'negras'. Deste modo se constituiu uma "divisão do trabalho sistemática e racializada" com efeito global - a categoria 'raça' tornou-se "por primeira vez no critério principal para a divisão da população mundial em estratos hierarquizados" e no "modo fundamental da classificação social universal da população mundial" (Quijano 2016, 31 e 29). De acordo com Quijano, esta classificação ainda hoje segue sendo atual: "O baixo nivel salarial das 'raças' inferiores para o mesmo trabalho que o dos brancos nos atuais centros capitalistas não poderia [...] ser explicado sem a classificação racista da população mundial - em outras palavras: não poderia ser explicado separadamente da colonialidade do poder capitalista global" (Quijano 2016, 38).
Essa visão representa um projeto alternativo às atuais concepções da história econômica, que aos olhos de Quijano seriam eurocêntricas, na medida em que aqui se enfatiza, por um lado, que o capitalismo desde o princípio foi um sistema econômico mundial, que teve seu início nas Américas; e, por outro, porque aqui a concepção de uma sequência histórica de formas de trabalho e produção - sobretudo a classificação de reciprocidade, escravidão e servidão como sendo pré-capitalistas - é interpretada de modo provinciano, porquanto limitada ao espaço interno europeu, e falso no contexto mundial (Quijano 2016, 64-66, 112s). Mas com sua perspectiva Quijano não desafia apenas a história econômica eurocêntrica. Em última análise ele problematiza toda a autocompreensão da Europa e sua relação com o mundo, o que é consequente na medida em que ele detecta no eurocentrismo a racionalidade especifica da colonialidade do poder (Quijano 2016, 23). A partir deste pano de fundo ele primeiro enfatiza o quanto a divisão da humanidade nos grandes grupos 'raciais' hierarquizados de brancos, 'índios' e negros tornou invisíveis diferenças e especificidades étnicas - uma vez que todos esses grandes grupos unificavam em si diferentes etnias e nações. De acordo com Quijado, isso tomou dos diferentes grupos populacionais suas identidades históricas especificas, e com isso se constitui em um inquestionável caso de negação cultural. Além disso Quijano enfatiza que a hierarquização das 'raças' denegou aos grupos populacionais não brancos tanto sua história especifica como seu lugar na história da produção cultural da humanidade - porquanto a divisão racial eurocêntrica relegou ao passado tudo o que fosse não europeu, e com isso desenvolveu um modelo temporal global, que funcionava de modo 'racial' e geográfico, a saber, na medida em que apresentava a Europa como a ponta-de-lança e, com isso, como presente e futuro do desenvolvimento global, atrás da qual todos os outros continentes eram desclassificados. Terceiro, por fim, Quijano defende a tese de que a Europa somente se constituiu "como consequência da América" - e não o contrário (Quijano 2016, 69). Essa tese não se refere unicamente à produção de conhecimento, 
a ideias de unidades continentais como aquela de América ou também (da branca) Europa. Para Quijano, a constituição da Europa como identidade e como unidade histórica "só foi possivel com o trabalho não-remunerado dos índios, dos negros e dos mestiços na América, com suas refinadas técnicas na mineração e agricultura, e por meio dos respectivos produtos: ouro, prata, batata, tomate, tabaco etc. etc." (Quijano 2016, 69). Isso significa que sem a América provavelmente a Europa não se tornaria assim como a conhecemos hoje, não apenas como ideia, mas também em sentido material. Significa, ademais, que essa Europa se fundamenta na exploração racializada de pessoas e espaços não europeus. Como diagnóstico da constituição tanto da estrutura da sociedade global como também da própria Europa isso não deixa de ser explosivo.

Ainda que Quijano descreva o caráter global da estruturação da sociedade, respectivamente do "modelo global de poder", a partir do pano de fundo acima esboçado como "colonial/moderno, capitalista e eurocêntrico", ele está longe de atribuir à modernidade europeia uma lógica livre de contradições (Quijano 2016, 63). Antes, a "modernidade colonial eurocêntrica" é para ele uma configuração "diversificada, internamente contraditória e conflitiva" (Quijano 2010, 36) - nesse contexto também seria possivel falar de dialética. No entanto, enquanto Adorno e Horkheimer silenciam sobre a colonialidade do poder em Dialética do esclarecimento (Horkheimer e Adorno 1982; Adorno e Horkheimer 2006) (e com isso, talvez deva-se dizer: antes reproduzem que criticam), para Quijano ela está no centro do paradoxo moderno. Porquanto a modernidade europeia se baseia, por um lado, "sobre as ideias de igualdade social, de solidariedade, de liberdade e autonomia de todas as pessoas, por outro lado, ela repousa sobre uma reclassificação social da população de toda a colonialidade de dominação eurocêntrica segundo os parâmetros da 'pertinência racial'" (Quijano 2010, 36). São, portanto, em primeira linha as diferenciações e classificações 'raciais' e colonial-racistas a serviço da dominação global que, para Quijano, garantem a inconsistência da modernidade.
Há mais um aspecto que é de particular importância em sua análise decolonial dos paradoxos da modernidade colonial: as contradições apontadas, segundo ele, não são em primeira linha de natureza teórica, mas sempre também práticas - a saber, na medida em que o colonialismo europeu era uma institucionalização de condições abusivas fora da Europa. De acordo com Quijano, é bem verdade que a Europa exportou para o mundo todo valores e instituições como igualdade social, liberdade, autonomia individual, cidadania e o moderno estado nacional, e com isso os globalizou. Mas ao mesmo tempo ela impediu sistematicamente que povos não brancos das suas colônias realizassem esses valores, e excluiu-os categoricamente da participação cidadã plena (Quijano 2010, 39). O fato de que o estado nacional do colonialismo de povoamento - desde o Cone Sul, isto é, desde os países na ponta ao sul da América Latina, passando pela América do Norte até a Austrália - via de regra era um estado nacional para colonizadores e colonizadoras que negava direitos fundamentais de cidadania justamente à população originária daqueles territórios até a atualidade recente, é um exemplo eloquente (Quijano 2016, 94S). Visto nessa perspectiva, portanto, as ambivalências da modernidade europeia vão muito além de esta conter o potencial para uma reversão em barbaridade e totalitarismo (Horkheimer e Adorno 1982, 3). Mais que isto: a modernidade colonial pode ser descrita como exportação concreta de barbárie e totalitarismo, o que, no entanto, é amplamente ignorado em suas autodescrições. Se isto estiver correto - e lamentavelmente há motivos para imputar-lhe isso -, então uma teoria crítica da política em tempos pós-coloniais que leva a sério seu posicionamento nos tempos atuais não poderá se limitar a distanciar-se de ideias (histórico-filosóficas) de progresso herdadas, como Amy Allen recomendou paradigmaticamente com a finalidade de uma descolonização das bases normativas da Teoria Crítica (Allen 2015). Antes, o que se faz necessário é submeter a uma revisão, além das bases normativas da tradição teórica, também suas ênfases em termos de conteúdo. Nisso parece importante, além das implicações teóricas da colonialidade 
do poder, também manter criticamente o foco em suas expressões empíricas, sua concretização na estruturação global da sociedade (Mendieta 2001; Enrique 2002; Kerner 2018b). Fazem parte disso seu eurocentrismo inerente da mesma forma que seu racismo e seu universalismo/imperialismo, que até hoje se expressa no mínimo sempre também como exportação de condições abusivas, como exportação de estruturas de exploração e mecanismos de exclusão.

\section{Modernidade, racismo e democracia}

O cientista político e historiador camaronês Achille Mbembe defende teses similares às de Quijano - ainda que as referências tanto teóricas como geográficas dos dois autores se diferenciem significativamente. Mbembe escreve na tradição advinda de Frantz Fanon ao invés daquela do aporte decolonial. Seu interesse, ademais, está voltado, sobretudo, à África, mais precisamente, ao colonialismo europeu na África, incluindo os efeitos de longo prazo tanto na própria África como também na Europa. ${ }^{5}$ Com isso, no centro de sua obra está um complexo de problemas que até agora permanece oculto na Teoria Crítica da Escola de Frankfurt, a saber, o racismo colonial em suas diferentes expressões: desde padrões de pensamento, que denegam a dignidade humana a grandes grupos de pessoas (não brancas) até institucionalizações desse tipo de padrão de pensamento no marco da política e economia coloniais e sua sobrevivência em tempos pós-coloniais. Já em seu artigo Necropolitica, publicado originalmente em 2003, Mbembe descreveu o racismo como "sombra sempre presente do pensamento e das práticas políticas ocidentais", que reaparece especialmente quando "se trata de pintar a suposta inumanidade de povos estranhos ou de exercer a dominação sobre eles" (Mbembe 2011, 68; cf. Mbembe 2016). Em seus livros mais recentes, sobretudo em Critica da razão negra, ele aprofundou a tese. Ele parte do pressuposto que a mencionada sombra do racismo de modo algum foi superada. "Seria um equívoco se a gente pensasse que deixamos definitivamente para trás aquele regime, cujas cenas originárias são o comércio com os negros escravos, seguido pelas colônias de plantagens e mineração" escreve Mbembe. E ao apontar para a conexão histórica entre racismo e capitalismo ele segue a mesma linha que Quijano. Isso se aplica também quando ele chama a atenção para a práxis surgida "nesta pia batismal de nossa modernidade", de aplicar "o princípio da raça e do sujeito homônimo sob o signo do capital" (Mbembe 2017a, 33; cf. Mbembe 2018). ${ }^{6}$ Mbembe também enfatiza a estreita ligação entre modernidade, colonialismo e racismo; ele não parte do pressuposto de que essa ligação entrementes estaria superada ou desfeita. Para fundamentar esse diagnóstico Mbembe expõe três momentos de uma contínua atualidade ou de reatualização daquilo que ele denomina "princípio da raça": primeiro, a reatualização biopolítica de diferenciações 'raciais' no contexto de tecnologias genéticas, biológicas e de segurança, sendo que essa última transforma sobretudo "o imigrante (legal ou ilegal) na figura de uma diferença de natureza essencial"; segundo, uma fase duradoura de acumulação primitiva, que "ainda recorre a meios auxiliares raciais"; e finalmente, terceiro, a circunstância que "guerra e raça sejam novamente problemas centrais da ordem internacional", que novamente se recorra a "processos de diferenciação, classificação e hierarquização" que têm como objetivo "exclusão, expulsão ou até destruição" (Mbembe 2017a, 53-55).

Dessa constelação segue para Mbembe que uma teoria crítica da modernidade necessita impreterivelmente uma teoria sistemática do racismo: "A crítica da modernidade permanecerá inconclusa enquanto não tivermos compreendido que seu surgimento coincide com o aparecimento do principio racial e com a lenta transformação desse princípio

\footnotetext{
5 O fato de as Américas, sobretudo com relação às plantagens e, com isso, aos inícios do capitalismo global baseado na escravização, também desempenhem um papel importante na análise de Mbembe se deve ao fato de que eram pessoas da África que foram subjugadas à escravidão nas Américas. Para um ensaio cultural-crítico extremamente influente sobre alguns dos efeitos de longo prazo dessa circunstância, a saber, a formação de uma cultura negra transatlântica, ver Paul Gilroy (2003).

6 Em semelhança a Quijano, Mbembe interpreta o Esclarecimento como ambivalente. "Seu objetivo é inserir os colonizados no espaço da modernidade. Mas seu caráter vulgar, sua brutalidade frequentemente indisfarçada e sua falsidade tornam-no em um exemplo perfeito do antiliberalismo" escreve ele (2017a, 185s).
} 
na matriz privilegiada das técnicas de dominação, e isto tanto hoje como outrora" escreve ele (2017a, 111). Essa inseparável conexão histórica, que se manifesta de modo evidente sobretudo nas colônias e pós-colônias europeias, é até o momento em boa medida uma lacuna temática no contexto da Teoria Crítica de influência frankfurtiana - e isso a despeito de essa conexão se tornar perceptível em muitos lugares - não por último na teoria e na práxis da democracia.

Com relação aos Estados Unidos da América, uma das colônias de povoamento europeias de outrora, Mbembe defende a tese de que as ideias modernas de liberdade, igualdade e democracia historicamente estavam conectadas "inseparavelmente com a realidade da escravidão" (2017a, 157) - e que a revolução estadunidense, que havia assumido para si justamente esses valores, se acomodou bem às práticas da escravidão e da divisão racial, ao invés de dar cabo a elas (2017a, 157). No livro Política da inimizade Mbembe aprofunda essas reflexões. Aos EUA ele atesta ali terem sido por longo tempo "um estado democrático escravocrata", que era caracterizado por uma divisão bipartite - uma "comunidade dos iguais" assim como "um grupo, igualmente estabelecido legalmente de não-iguais ou de pessoas sem participação", aos quais é negado o direito a ter direitos (2020, 36s; 2017b). A indicação de um mundo colonial bipartido, "separado em compartimentos", é bem conhecida a partir dos escritos de Frantz Fanon - ele considerava que análises críticas da "instituição" ou "da forma geográfica" de sociedades coloniais fazia sentido porque elas possibilitariam "determinar a estrutura a partir da qual a sociedade decolonializada se inicia" (2020, 31; 2010). Com relação ao estado democrático escravocrata, que é um estado pós-colonial, seria possivel afirmar a partir desse pano de fundo que a estrutura herdada, a constituição colonial da sociedade, permanecera intacta em todos os lugares. E também com relação a nosso presente e futuro - nos EUA, na Europa, na América Latina, na África do Sul e em outros lugares - Mbembe considera que o racismo antes foi preservado do que tenderá a desaparecer. Exemplos não the faltam: ao lado do racismo cotidiano (parcialmente inconsciente) ele menciona sobretudo a produção estatal de clandestinos e ilegais, deportações e racial profiling (Mbembe 2020, 107-111). "Ao fim e ao cabo, portanto, não subsistem democracias liberais sem esse acréscimo em serviçal e racista, em colonial e imperial" conclui ele. Essa "divisão já ocorrida no início" seria antes seu atributo (histórico) $(2020,121)$.

\section{Imperialismo ontem e hoje}

A tese de Mbembe, segundo a qual a democracia liberal moderna apresenta desde o início uma feição imperial, é compartilhada também pelo cientista político canadense James Tully. Ele está menos interessado no emprego de diferenciações racistas do que no estabelecimento de instituições legais e políticas que servem à dominação ocidental - e ele problematiza o fato de que nas ciências sociais modernas isso via de regra é ignorado ao invés de criticado. Tully diferencia entre duas variantes do jogo imperialista: o colonialismo imperialista e uma variante mais recente, que consegue se impor sem colônias, a qual ele designa como "imperialismo informal" (2009, 153). O imperialismo informal unifica - como já fazia o imperialismo colonial - aspectos econômicos e políticos e funciona através da interação dentro de uma configuração intraestatal e político-mundial específica (válida para as áreas de influência imperial). Internamente aos estados, ele ocorre através da imposição de uma estrutura do direito público e do estabelecimento de instituições políticas correspondentes, eventualmente também através da adaptação estrutural de uma ordem constitucional já estabelecida, com o objetivo de obter "acesso do livre mercado dominado pelas grandes potências aos recursos, à força de trabalho e aos mercados do país dominado". Em termos de política mundial, isso se dá pela subjugação da recém-criada ou re-formada ordem sob regimes legais internacionais, que estão igualmente a serviço das grandes potências (Tully 2009, 156). De acordo com Tully, no marco dessa ordem os países subordinados são reconhecidos como estados constitucionais soberanos - mas isso ocorre 
a partir do pano de fundo de imensas assimetrias de poder, que se estendem desde a economia, passando pela política e pelo direito, incluindo também a cultura e as forças armadas, e que "foram estabelecidas no transcurso da secular expansão ocidental" - razão pela qual neste contexto Tully fala de uma "dominação interativa entre soberanos com direitos desiguais" e de "imperialismo do inimigo" (2009, 196, 195). O sistema westfaliano de estados ele descreve a partir desse pano de fundo como "sistema imperial de estados hegemônicos e subordinados". Sem esse sistema, o imperialismo informal permaneceria "praticamente sem efeito" (2009, 164).

Visto em perspectiva histórica, isso significa que os estados constitucionais europeus se desenvolveram "desde o início dentro de sistemas globais do direito imperial e colonial", e não adentraram contextos constitucionais inter e transnacionais apenas depois de seu estabelecimento (Tully 2009, 201). Países pós-coloniais de qualquer modo estão profundamente enraizados no colonialismo já pelo simples fato de que dificilmente até mesmo o transcurso de suas fronteiras territoriais externas poderia ser desconectado da história colonial, e com isso, da história de intervenções externas. Os estados independentes e soberanos fora da Europa que foram reconhecidos no marco do direito dos povos são, segundo Tully, justamente "as ex-colônias cujas estruturas legais e politicas foram construidas pelas potências europeias com vistas a seus próprios interesses durante dois periodos do imperialismo colonial" - aquele primeiro período entre 1500 e 1776, que também está no centro da análise de Quijano, bem como um segundo período da "'hipercolonização' entre 1800 e 1905 , durante o qual $85 \%$ do mundo não europeu estavam submetidos à dominação imperial (formal ou informal)" (2009, 162). Aquilo que ocorreu depois da descolonização no século 20 também tem pouco a ver com soberania e autodeterminação. Tully esclarece em uma frase única e, com isso, com uma frase de literalmente tirar o fôlego:

\begin{abstract}
Para sobreviver no sistema mundial imperial, no qual se encontravam, as elites nacionais foram ao mesmo tempo motivadas e forçadas a modernizar seus povos etnicamente diversos e o interior de seus paises, processo no qual frequentemente se usou de grande violência contra as ordens legais e politicas tradicionais; a introduzir fronteiras territoriais claramente definidas e uma nacionalidade unificada ali onde antes não as havia; a fortalecer as instituições ocidentalizadas do direito, da política e militares do periodo colonial face ao pluralismo autóctone do direito e da política; a abrir suas portas para uma economia mundial capitalista complexamente formada (ou, até 1989, para a economia socialista), sobre a qual não tinham controle e que foi estabelecida às custas do controle local sobre as próprias questões econômicas; a subordinar sua soberania legal e politica sobre os próprios recursos ao direito internacional e aprender a designar essa subordinação imperial como 'liberdade'; a acumular monstruosas dividas para sobreviverem na concorrência pelo desenvolvimento; a tomar em conta relações crescentes de dependência e endividamento na corrida armamentista; e, finalmente, por consequência destas relações de dependência, a submeter-se aos programas de modernização periodicamente criados desde os anos 1960 pelas novas instituições do imperialismo pós-colonial informal, ou seja, pelo FMI, Banco Mundial, Gatt e diversos acordos comerciais da OMC. (Tully 2009, 163).7
\end{abstract}

Que este programa imposto a partir de fora estaria amplamente fadado ao fracasso, isso praticamente nem precisa ser dito. Segundo Tully, em muitos casos ele levou a uma resistência da população contra suas elites nacionais ocidentalizadas, o que por sua vez fomentou sua dependência de dominações militares e impediu processos de democratização. A consequência foi uma organização estatal fraca ou 'fracassada' - o que uma vez mais abriu portas para formas de exercício de influência imperial. Com relação a isso, Tully explica que "só muito poucos imperialistas liberais fazem menção ao fato que os próprios estados fracassados são um produto das ondas formais ou informais de 'replicação' imperial da formação de estados nacionais, por um lado, e, por outro, de lutas de resistência de povos que sonham em construir suas próprias

\footnotetext{
7 Uma análise similar pode ser encontrada em Fanon (2020, 127-151). Para obter uma visão panorâmica do fluxo da argumentação desse livro, ver também Kerner (2018a).
} 
formas de uma comunidade política" (2009, 164). Condições abusivas, que estão inequivocamente conectadas com a instituição da estrutura social imperial, portanto sequer são descritas como tais nas exposições daqueles imperialistas neoliberais. Elas são antes tomadas como oportunidade para impulsionar novas ondas de exercício de influência imperial. Segundo Tully, o fomento, a canalização e a limitação da autodeterminação e das liberdades democráticas dos estados subordinados se constitui em um dos principais instrumentos da dominação imperial (2009, 179). Contudo, com esse instrumento de modo algum se apoia formas robustas de democracia - antes, na democracia apoiada imperialmente trata-se de "democracias de baixa intensidade", ou de uma forma de "democracia representativa de elites, dependente de relações comerciais e militares com o exterior e que se opõe tendencialmente às aspirações de participação democrática da maioria da população" (2009, 183). Ainda de acordo com Tully, isso não é uma alternativa ao imperialismo - para isso seriam necessárias formas robustas de democracia tanto em nivel local como global, bem como o fomento de autodeterminação e republicanismo verdadeiros. Sobre isso, ele aclara: "Não se pode enfrentar o imperialismo simplesmente estendendo as formas dominantes da democracia representativa neoliberal ou social-democrática a outros estados" (2009, 185) - pois no caso de tais extensões não se trataria de outra coisa que "formas impostas do direito e da democracia", que "são controladas indiretamente através das técnicas do imperialismo informal" (2009, 185).

A análise de Tully mostra que uma apreciação história que leva a sério a história e o presente do imperialismo ocidental e, a partir desse pano de fundo, assume uma perspectiva global para além do eurocentrismo, possibilita uma visão substancialmente diferente, mais critica, de formas atuais da democracia constitucional do que uma apreciação que negligencia isso. De acordo com Tully, análises que se limitam à história da democracia constitucional nos estados ocidentais, ao contrário, não são adequadas para contribuir significativamente para a compreensão dessas instituições (2009, 213). ${ }^{8}$ Esse pensamento contém um desafio claro para a tradição da Teoria Crítica, fortemente orientada nas experiências e constelações da Europa Ocidental e da América do Norte.

\section{Política pós-colonial e sexualidade}

Quando se observa estas questões em uma perspectiva feminista, em sua maioria elas se revelam um pouco mais complexas do que de uma perspectiva não feminista. Por exemplo: ao modelo unificador de racismo e capitalismo em Quijano, Maria Lugones acrescenta como terceiro eixo gênero e sexualidade. Isso porque, segundo ela, o moderno colonialismo estabeleceu um sistema colonial/moderno generificado. Com essa descrição ela aponta para um sistema diferenciado de normatização da sexualidade, que por um lado - quando referido a brancos - propagava o modelo da pequena familia heterossexual burguesa, e que, de acordo com o contexto decorrente das diversas expressões da paginação colonial, implicava na repressão a formas alternativas de gênero e sexualidade - e que introduziu uma hierarquização da sexualidade bipolar como um mecanismo omnipresente de estruturação social que em muitos lugares até então sequer existia (Lugones 2007). Posteriormente, em parte também em outros lugares, as metrópoles se perfilavam como guardiãs da justiça de gênero - um modelo discursivo que ainda se pode observar frequentemente mesmo em tempos pós-coloniais. Nesse sentido, em seu livro Politica da inimizade, Mbembe resume a lógica da política de gênero pós-colonial como segue: "A manipulação das questões de gênero com fins racistas, contornada através da referência à supremacia masculina no outro, em geral serve à finalidade de disfarçar a realidade da falocracia na própria sociedade" (2020, 113).9 A interpretação depreciativa do modo "como negros ou muçulmanos árabes tratam 'suas mulheres'" tem, segundo Mbembe, "como já em tempos coloniais [...] algo de uma mescla de voyerismo

\footnotetext{
8 Sobre as estratégias da historização (colonial) na teoria política, ver Kerner (2016).

9 Sobre a longa tradição do outrear do sexismo e da critica feminista a essa tradição, ver também Kerner (2009).
} 
e lascivia - a lascivia do harém" (2020, 113). Pode ser desconsiderado por hora que na formulação dessa observação ele provavelmente tenha tido em mente antes intérpretes heterossexuais masculinos que femininos; importante é em todo caso ter ressaltado que se trata aqui de uma velha tradição do outrear (othering) o sexismo que já era florescente nos tempos do imperialismo colonial europeu. Naqueles casos, nos quais o colonialismo andava associado a uma missão civilizatória, o outrear do sexismo tornara-se parte integral dessa missão - na medida em que não se contentava em atribuir sexismo aos colonizados, mas relacionava ademais a ordem colonial com o desejo de impor justiça de gênero, pelo menos retoricamente. Gayatri Chakravorty Spivak cunhou para isso a acertada expressão "homens brancos que salvam mulheres morenas de homens morenos" (2011, 78; Spivak 2010). E já Frantz Fanon descreveu como a administração colonial francesa na Argélia assumiu para si a tarefa de assegurar "a destruição da peculiaridade do povo", e com essa finalidade convencer as argelinas a abandonarem o uso do véu e, sobretudo, levá-las à colaboração mediante o lema: "Se nós conquistarmos as mulheres, então teremos vencido a luta" $(1969,21)$. Ponto de partida para isso foi o diagnóstico de uma estrutura social paternalista, contra a qual se desejava mobilizar as argelinas. Segundo Fanon, a potência de ocupação queria "defender a mulher humilhada, deixada de lado, trancada" - e com esse fim ela ressaltou os grandes potenciais da mulher que, no entanto, "infelizmente foi transformada pelo homem argelino num objeto passivo, degradado, ou seja, desumanizado"; o comportamento do argelino foi "denunciado como medieval e bárbaro" (1969, 22).

Com base no horizonte normativo do feminismo liberal seria, pois, possivel constatar que a relação entre os sexos na Argélia colonial - do mesmo modo que na colonizadora França - não eram efetivamente moldadas pelo igualitarismo. E a Fanon se poderia acusar de ter tido pouco interesse numa interpretação complexa feminista da política francesa de gênero na Argélia colonial, embora com o estudo de Simone de Beauvoir $O$ segundo sexo, publicado em 1949, o instrumental analítico para tal empreendimento claramente estaria à disposição (2021; cf. Beauvoir 2009). Ao invés disso, ele desqualificou aquelas mulheres que efetivamente deixaram de usar o véu como "mulheres modelo" que perambulam por ai "com rosto desnudo e corpo livre como moeda da sociedade europeia" (Fanon 1969, 26). Mas a despeito destas restrições, a exposição de Fanon sobre a política colonial de gênero são esclarecedoras, porquanto elas conduzem o foco para as lutas e os deslocamentos que a política colonial de gênero provocou - em especial com relação ao véu. A extraordinária importância dessa peça de roupa, segundo sua análise, de modo algum era pré-política, senão que, ao contrário, era um efeito justamente daquela politica colonial que a colocava no seu centro. De acordo com Fanon, as pessoas colonizadas enfrentavam a "ofensiva [político-colonial] contra o véu" com um "culto ao véu" - a postura das argelinas para com ele foi doravante correlacionada "com sua postura geral face à potência colonizadora" (Fanon 1969, 31).

O fato que as relações entre os gêneros (incluindo-se a vestimenta feminina) em muitas constelações coloniais tenham se transformado num elemento integral, em um joguete e símbolo da confrontação entre ordem colonial e forças anticoloniais, ainda hoje leva a significativos problemas para atoras feministas, em especial no Sul global. Seguindo-se a filosofia de Uma Narayan, que em suas reflexões tem, entre outros, o contexto indiano como referência, então faz parte das consequências tardias da instrumentalização das relações de gênero para a imposição das reivindicações coloniais de poder não por último também a circunstância que lutas feministas ou mesmo simples aspirações emancipatórias femininas individuais sejam ainda hoje frequentemente curto-circuitadas com ideias ocidentais e rejeitadas por forças antifeministas como imperialismo cultural. Narayan critica enfaticamente esse tipo de instrumentalização da relação Norte-Sul para a imposição de reivindicações patriarcais de poder. Segundo ela, as tentativas de rechaçar as perspectivas e lutas de feministas no Sul global como "ocidentalizadas" deveriam por seu turno ser combatidas, a saber, 
de um lado mediante a referência ao emprego seletivo e egoista da acusação de ocidentalização, e, por outro, através da ênfase nas respectivas raizes e motivações das referidas perspectivas e lutas. "Feministas do Terceiro Mundo necessitam apontar urgentemente para as mudanças efetivas em seus contextos para que nossas ênfases temáticas não sejam deslegitimadas através de apelos a 'tradições imutáveis'", escreve ela. Em outra passagem do mesmo texto ela aponta que o projeto do nacionalismo indiano no século 19 consistia numa apropriação seletiva da modernidade europeia e que ainda hoje a Índia - como possivelmente todas pós-colonias - está marcada por uma interação complexa entre estruturas locais e coloniais (Narayan 2001, 377, 374, 366).

Também Gayatri Spivak, em sua análise feminista da politica colonial e pós-colonial, não se limita a acusar a instrumentalização da questão de gênero pelos colonizadores. Segundo ela, também o patriarcado indiano não estava ao lado das mulheres. Nas disputas em torno da proibição do satī, do sacrificio das viúvas, ela contrapõe à aspiração colonial britânica, de libertar mulheres aborigenes de sua tradição patriarcal, o "argumento nativista indiano", que enfatizava a suposta voluntariedade e, com isso, a capacidade de ação das viúvas que se sacrificavam: "As mulheres efetivamente querem morrer" dizia a frase complementar à famosa afirmação de Spivak sobre "homens brancos que salvam mulheres morenas de homens morenos" (2011, 81). Segundo Spivak, em ambas as lógicas a mulher subalterna é silenciada. Em seu conteúdo, ela claramente concorda com a eliminação do satī pelos britânicos - é esse tipo de polarização dessa questão de ambos os lados que é objeto de sua critica (2011, 84). Mas isso significa também que, em sua perspectiva pós-colonial feminista, não basta submeter as lógicas e práticas do imperialismo cultural a uma análise crítica. Antes, é necessário incluir em tal análise também as lógicas e práticas dos subjugados ao colonialismo - pois por um lado não se pode pressupor que se trate de grupos homogêneos e livres de poder e hierarquias em suas relações internas, e, por outro, é preciso pressupor que as lógicas e práticas do colonialismo justamente também subjetivam aqueles que a ele estão subjugados e os afetam com relação a suas opções de ação e de tomadas de decisões, e isso provavelmente não apenas exclusivamente em sentido positivo. Ademais, existe uma perspectiva pós-colonial feminista de sempre questionar a política colonial e pós-colonial com relação a seus efeitos em termos de gênero - mesmo quando a resposta resultante seja um pouco mais complexa, não por último porque dificilmente se pode decidir taxativamente que sempre e em cada questão se deveria dar prioridade a um patriarcado ancestral frente a um patriarcado colonial. Spivak, por exemplo, não rejeita categoricamente a produção do sujeito colonial, o "acesso ao esclarecimento europeu através do colonialismo", mas caracteriza ambos como "lesionamento capacitante" - para ao mesmo tempo defender que se utilize a capacitação com a finalidade do combate à injustiça "enquanto a lesão é novamente negociada" (Spivak 2008, 8, 79 n. 2). Obviamente que uma caracterização como essa não torna o imperialismo colonial europeu melhor em nada. O que a torna potencialmente melhor é uma profunda análise critica da política de gênero global e globalmente afetada num mundo pós-colonial.

\section{Considerações finais}

A teoria crítica de influência frankfurtiana em seu início estava concentrada na Europa Ocidental e na América do Norte. Entrementes ela se livra gradativamente dessa concentração, pelo menos parcialmente. Com isso ela reage à circunstância de que nosso mundo, inclusive suas diferenças, transformações e desigualdades, dificilmente poderá ser compreendido se a análise for limitada a umas poucas regiões, ainda por cima regiões muito privilegiadas. Porquanto nosso mundo globalizado - segundo nos ensinam autores como Quijano e Tully - não tem apenas algumas décadas, mas meio milênio, pois foi então que iniciou a primeira fase do imperialismo colonial europeu. Desde então estamos diante de uma estruturação social global fortemente moldada pela história e pelo presente do imperialismo ocidental. $\mathrm{O}$ fato que essa influência praticamente não seja discutida 
nos antigos e atuais centros desse imperialismo pode ser visto como sintomático. Porquanto a base justificadora do colonialismo sempre foi a de que justamente não se tratava de injustiça, mas antes de medidas legítimas - sendo que esta óbvia autolegitimação via de regra era realizada através daquele subterfúgio que Mbembe denomina princípio racial. Mbembe esclarece ademais que o racismo não serviu apenas para a legitimação da tomada da terra, opressão e exploração coloniais, mas ademais estruturou a economia, a política e a sociedade - nas próprias colônias, mas também ali onde o empreendimento colonial foi organizado. Quijano demonstra em que medida o racismo foi, desde o início, um componente integral do capitalismo global. E Tully ainda acrescenta que também nosso sistema estatal está radicado profundamente no imperialismo ocidental.

Levando-se em consideração essas análises, fica bastante óbvio que todo projeto teórico crítico interessado em "condições razoáveis" necessita se dedicar precisamente a estas interconexões, precisa levar a sério a colonialidade do poder juntamente com suas múltiplas implicações, e isto com relação às mais diversas esferas da política e da sociedade. Pode-se mencionar, por exemplo, as questões ligadas a fronteiras, refúgio, migração, a regulação da cidadania, guerra e políticas de paz, ou também o vasto campo da política de ajuda para o desenvolvimento. Tomar a colonialidade do poder a sério implica, ademais, colocar conscientemente um fim em sua evidente não tematização que caracterizou e ainda caracteriza a teoria política ocidental. Isto é uma convocação política, pelo menos em um primeiro momento uma convocação político-discursiva, mas também um postulado metodológico para toda teoria que tenha pretensão de ser crítica. Uma problematização explícita é diferente, algo potencialmente de alcance muito maior do que uma problematização implicita, ainda que essa possa ser um importante primeiro passo. Como pode ser uma tematização explícita e ao mesmo tempo crítica, isso a teoria pós-colonial mostra há anos. ${ }^{10}$

\section{Referências}

Adorno, Theodor W. e Max Horkheimer. 2006. Dialética do esclarecimento: fragmentos filosóficos. Traduzido por Guido Antônio de Almeida e Theodor W. Adorno. Rio de Janeiro: Zahar.

Allen, Amy. 2015. The end of progress: decolonizing the normative foundations of critical theory. New York: Columbia University Press. https://doi.org/10.7312/ alle17324.

Beauvoir, Simone de. 2009. O segundo sexo. Rio de Janeiro: Nova Fronteira.

Beauvoir, Simone de. 2021. Das andere Geschlecht: Sitte und Sexus der Frau. Traduzido por Uli Aumüller e Grete Osterwald. 23. ed. Reinbek bei Hamburg: Rowohlt Taschenbuch Verlag.

Enrique, Dussel. 2002. Six theses towards a critique of political reason: the citizen as political agent. In The Political, organizado por David Ingram, 265-279. Blackwell Readings in Continental Philosophy. Malden: Blackwell Publishers.

Fanon, Frantz. 1969. Aspekte der Algerischen Revolution Frankfurt am Main: Suhrkamp.

Fanon, Frantz. 2010. Os condenados da terra. Juiz de Fora: Editora UfJF.

Fanon, Frantz. 2020. Die Verdammten dieser Erde. Traduzido por Traugott König. 18 ed. Suhrkamp-Taschenbuch 668. Frankfurt am Main: Suhrkamp.

Gilroy, Paul. 2003. The Black Atlantic: modernity and double consciousness. 8 ed. Cambridge: Harvard Univ. Press.

Horkheimer, Max. 1980. Teoria Tradicional e Teoria Crítica. In Textos escolhidos, organizado por Walter Benjamin, Max Horkheimer, Theodor W. Adorno e Jürgen Habermas, 117-161. São Paulo: Abril.

Horkheimer, Max, e Theodor W. Adorno. 1982. Dialektik der Aufklärung. Frankfurt am Main: Suhrkamp.

Kerner, Ina. 2009. Differenzen und Macht: zur Anatomie von Rassismus und Sexismus. Reihe Politik der Geschlechterverhältnisse, vol. 37. Frankfurt am Main: Campus.

Kerner, Ina. 2016. Jenseits des politiktheoretischen Eurozentrismus: Strategien einer Dekolonisierung. In Transkulturelle politische Theorie: eine Einführung. organizado por Sybille de la Rosa, Sophia Schubert, e Holger Zapf, 113-133. Trans- und interkulturelle politische Theorie und Ideengeschichte. Wiesbaden: Springer VS. http://doi.org/10.1007/978-3-658-05010-8.

Kerner, Ina. 2018a. Frantz Fanon, die Verdammten dieser Erde (1961). In Geschichte des politischen Denkens: das 20. Jahrhundert, organizado por Manfred Brocker, 381-395. Suhrkamp taschenbuch wissenschaft 2210. Berlin: Suhrkamp.

10 Uma versão anterior, um pouco mais longa, deste artigo foi publicada sob o título "Zu einer kritischen Theorie der Politik in postkolonialen Zeiten" (Kerner 2019) 
Kerner, Ina. 2018b. Beyond Eurocentrism: trajectories towards a renewed political and social theory. Philosophy \& Social Criticism 44 (5): 550-570. http://doi. org/10.1177/0191453717752768.

Kerner, Ina. 2019. Zu einer kritischen Theorie der Politik in Postkolonialen Zeiten. In Kritische Theorie der Politik, organizado por Ulf Bohmann e Paul Sörensen, 650-671. Suhrkamp 2263. Berlin: Suhrkamp.

Lugones, María. 2007. Heterosexualism and the colonial/modern gender system. Hypatia 22 (1): 186-219. http://doi.org/10.1111/j.1527-2001.2007.tb01156.x.

Mbembe, Achille. 2011. Nekropolitik. In Biopolitik-in der Debatte, organizado por Marianne Pieper, 63-96. Wiesbaden: VS Verlag für Sozialwissenschaften. https:// doi.org/10.1007/978-3-531-92807-4_3.

Mbembe, Achille. 2016. Necropolítica: biopoder soberania estado de exceção política da morte. Arte \& Ensaios 32: 122-151.

Mbembe, Achille. 2017a. Kritik der schwarzen Vernunft. Traduzido por Michael Bischoff. Berlin: Suhrkamp.

Mbembe, Achille. 2017b. Politicas da inimizade. Lisboa: Antigona.

Mbembe, Achille. 2018. Crítica da razão negra. São Paulo: N-1 Edições.

Mbembe, Achille. 2020. Politik der Feindschaft. Traduzido por Michael Bischoff. 2. ed. Berlin: Suhrkamp Taschenbuch Wissenschaft.

Mendieta, Eduardo. 2001. Chronotopology: critique of spatiotemporal regimes. In New Critical Theory: essays on liberation, organizado por William S. Wilkerson e Jeffrey R. Paris, 175-797. New Critical Theory. Lanham: Rowman \& Littlefield Publishers.

Mignolo, Walter. 2005. The idea of Latin America. Blackwell manifestos. Malden, Oxford: Blackwell Pub.

Mignolo, Walter D. e Arturo Escobar, orgs. 2013. Globalization and the decolonial option. London New York: Routledge, Taylor \& Francis Group.

Moraña, Mabel, Enrique D. Dussel e Carlos A. Jáuregui, orgs. 2008. Coloniality at large: Latin America and the postcolonial debate. Latin America otherwise. Durham: Duke University Press.

Narayan, Uma. 2001. Kulturen in der Auseinandersetzung - 'Verwestlichung', Respekt für Kulturen und Dritte-Welt-Feministinnen. In Die andere Hälfte der Globalisierung: Menschenrechte, Ökonomie und Medialität aus feministischer Sicht, organizado por Steffi Hobuss, 337-393. Frankfurt am Main: Campus.

Quijano, Anibal. 2007. Coloniality and modernity/rationality. Cultural Studies 21 (2-3): 168-178. https:// doi. org/10.1080/09502380601164353.

Quijano, Anibal. 2010. Die Paradoxien der eurozentrierten kolonialen Moderne. Prokla. Zeitschrift für Kritische Sozialwissenschaft 40 (158): 29-47. https://doi. org/10.32387/prokla.v40i158.399.
Quijano, Anibal. 2014. Cuestiones y horizontes: de la dependencia histórico-estructural a la colonialidad/ descolonialidad del poder: antologia esencial. Organizado por Danilo Assis Clímaco. Colección Antologías. Buenos Aires: Clacso.

Quijano, Anibal. 2016. Kolonialität der Macht, Eurozentrismus und Lateinamerika. Organizado por Tom Waibel. Traduzido por Alke Jenss, Stefan Pimmer e Jens Kastner. Es kommt darauf an: Texte zur Theorie der politischen Praxis, Band 17. Wien Berlin: Verlag Turia + Kant.

Quintero, Pablo e Sebastian Garbe, orgs. 2013. Kolonialität der Macht: de/koloniale Konflikte: zwischen Theorie und Praxis. Münster: Unrast.

Spivak, Gayatri Chakravorty. 2008. Righting wrongs: Unrecht richten. Traduzido por Sonja Finck e Janet Keim. Transpositionen. Zürich: diaphanes.

Spivak, Gayatri Chakravorty. 2010. Pode o subalterno falar? Traduzido por Sandra Regina Goulart Almeida, Marcos Pereira Feitosa e André Pereira Feitosa. Belo Horizonte: Editora UFMG.

Spivak, Gayatri Chakravorty. 2011. Can the subaltern speak? Postkolonialität und subalterne Artikulation. Traduzido por Alexander Joskowicz, Stefan Nowotny, e Hito Steyerl. Es kommt darauf an 6. Wien: Turia + Kant.

Tully, James. 2009. Politische Philosophie als kritische Praxis. Traduzido por Eva Engels e Rainer Forst. Theorie und Gesellschaft 62. Frankfurt am Main: Campus-Verl.

\section{Ina Kerner}

Doutora em Ciência Politica pela Freie Universität Berlin, Berlim, Alemanha, com atuações em diversas universidades do Sul (Guatemala, África do Sul, Paquistão, Brasil) e do Norte (EUA, Grã-Bretanha) globais. Professora de ciência política e diretora do Instituto para Ciência da Cultura da Universidade de Koblens-Landau, Koblens, Alemanha. 